\title{
Variable Association of Reactive Intermediate Genes with Systemic Lupus Erythematosus in Populations with Different African Ancestry
}

\author{
Paula S. Ramos, James C. Oates, Diane L. Kamen, Adrienne H. Williams, Patrick M. Gaffney, \\ Jennifer A. Kelly, Kenneth M. Kaufman, Robert P. Kimberly, Timothy B. Niewold, \\ Chaim O. Jacob, Betty P. Tsao, Graciela S. Alarcón, Elizabeth E. Brown, Jeffrey C. Edberg, \\ Michelle A. Petri, Rosalind Ramsey-Goldman, John D. Reveille, Luis M. Vilá, Judith A. James, \\ Joel M. Guthridge, Joan T. Merrill, Susan A. Boackle, Barry I. Freedman, R. Hal Scofield, \\ Anne M. Stevens, Timothy J. Vyse, Lindsey A. Criswell, Kathy L. Moser, \\ Marta E. Alarcón-Riquelme, Carl D. Langefeld, John B. Harley, and Gary S. Gilkeson
}

ABSTRACT. Objective. Little is known about the genetic etiology of systemic lupus erythematosus (SLE) in individuals of African ancestry, despite its higher prevalence and greater disease severity. Overproduction of nitric oxide (NO) and reactive oxygen species are implicated in the pathogenesis and severity of SLE, making NO synthases and other reactive intermediate-related genes biological candidates for disease susceptibility. We analyzed variation in reactive intermediate genes for association with SLE in 2 populations with African ancestry.

Methods. A total of 244 single-nucleotide polymorphisms (SNP) from 53 regions were analyzed in non-Gullah African Americans (AA; 1432 cases and 1687 controls) and the genetically more homogeneous Gullah of the Sea Islands of South Carolina (133 cases and 112 controls). Single-marker, haplotype, and 2-locus interaction tests were computed for these populations.

Results. The glutathione reductase gene GSR (rs2253409; p = 0.0014, OR 1.26, 95\% CI 1.09-1.44) was the most significant single SNP association in AA. In the Gullah, the NADH dehydrogenase NDUFS4 (rs381575; $\mathrm{p}=0.0065$, OR 2.10, 95\% CI 1.23-3.59) and NO synthase gene NOS1 (rs561712; $\mathrm{p}=0.0072$, OR $0.62,95 \%$ CI $0.44-0.88$ ) were most strongly associated with SLE. When both populations were analyzed together, GSR remained the most significant effect (rs2253409; $\mathrm{p}=$ 0.00072 , OR 1.26, 95\% CI 1.10-1.44). Haplotype and 2-locus interaction analyses also uncovered different loci in each population.

Conclusion. These results suggest distinct patterns of association with SLE in African-derived populations; specific loci may be more strongly associated within select population groups. (First Release May 1 2013; J Rheumatol 2013;40:842-9; doi:10.3899/jrheum.120989)

Key Indexing Terms:

SYSTEMIC LUPUS ERYTHEMATOSUS AFRICAN AMERICANS OXYGEN COMPOUNDS GENETIC ASSOCIATION STUDIES SINGLE-NUCLEOTIDE POLYMORPHISM

\footnotetext{
From the Department of Medicine, Medical University of South Carolina, Charleston, South Carolina, USA; Wake Forest School of Medicine and Center for Public Health Genomics, Winston-Salem, North Carolina, USA; Arthritis and Clinical Immunology Research Program, and Clinical Pharmacology Research Program, Oklahoma Medical Research Foundation, Oklahoma City, Oklahoma, USA; Division of Rheumatology, Cincinnati Children's Hospital Medical Center, Cincinnati, Ohio, USA; Department of Medicine, School of Medicine, and Department of Epidemiology, School of Public Health, University of Alabama at Birmingham, Birmingham, Alabama, USA; Section of Rheumatology and Gwen Knapp Center for Lupus and Immunology Research, University of Chicago, Chicago, Illinois, USA; Keck School of Medicine, University of Southern California, Los Angeles, California, USA; David Geffen School of Medicine, University of California, Los Angeles, California, USA; Department of Medicine, Johns Hopkins University School of Medicine, Baltimore, Maryland, USA; Division of Rheumatology, Northwestern University Feinberg School of Medicine, Chicago, Illinois, USA; Rheumatology and Clinical Immunogenetics, University of Texas Health
}

\author{
Science Center at Houston, Houston, Texas, USA; Department of \\ Medicine, Division of Rheumatology, University of Puerto Rico Medical \\ Sciences Campus, San Juan, Puerto Rico; Department of Medicine, \\ University of Oklahoma Health Sciences Center, Oklahoma City, \\ Oklahoma, USA; Division of Rheumatology, University of Colorado \\ Denver, Aurora, Colorado, USA; Department of Internal \\ Medicine/Nephrology, Wake Forest School of Medicine, Winston-Salem, \\ North Carolina, USA; US Department of Veterans Affairs Medical Center \\ Oklahoma City, Oklahoma, USA; Division of Rheumatology, Department \\ of Pediatrics, University of Washington, Seattle, WA, USA; King's College \\ London, Divisions of Genetics and Molecular Medicine and Immunology, \\ Infection and Inflammatory Disease, London, UK; Rosalind Russell \\ Medical Research Center for Arthritis, University of California, San \\ Francisco, California, USA; and Centro de Genómica e Investigaciónes \\ Oncológicas, Pfizer-Universidad de Granada-Junta de Andalucia, \\ Granada, Spain. \\ Supported by the South Carolina Clinical and Translational Research \\ (SCTR) Institute, through US National Institutes of Health (NIH) grant
}


numbers UL1 RRO29882 and UL1 TR000062; by NIH grant numbers R01 AR45476 (JCO), U54 RR026107 (JCO), R01 AI063274 (PMG), P01 $A R 49084$ (RPK, CDL, JBH, EEB, JCE, JDR, RRG, MAP, LMV), RO1 AR043274 (CDL, KLM), R01 AR33062 (RPK), R01 AR445650 (COJ), R01 AR043814 (BPT), P01 AR49084 (GSA), P30 AR055385 (EEB), $5 U L 1$ RR025777 (JCE), AR43727 (MAP), K24 AR002138 (RRG), P60 2 AR30692 (RRG), UL 1 RR025741 (RRG), AI082714 (JAJ, JMG), AI101934 (JAJ), AR053843 (JAJ, JMG), AR058554 (JAJ, JMG), RR031152 (JAJ, JMG), R01 AR44804 (LAC), K24 AR02175 (LAC), P60 AR053308 (LAC), 5 M01 RR-00079 (LAC), RR020143 (KLM, MAR), AR042460 (JBH), AI024717 (JBH), AR062277 (JBH); and by the US Department of Veterans Affairs (JBH), the Mary Kirkland Scholarship (JBH, LAC), the Instituto de Salud Carlos III (PSO9/00129 to MAR), FEDER funds of the European Union (MAR), the Lupus Foundation of Minnesota (KLM), arc project grant 17761 (TJV), Wellcome Trust programme grant 085492 (TJV), the Lupus Research Institute (BPT), Wake Forest School of Medicine Center for Public Health Genomics, and the Alliance for Lupus Research (COJ, LAC).

P.S. Ramos, PhD; J.C. Oates, MD; D.L. Kamen, MD; G.S. Gilkeson, MD, Division of Rheumatology and Immunology, Department of Medicine, Medical University of South Carolina; A.H. Williams, MA; C.D. Langefeld, PhD, Wake Forest School of Medicine and Center for Public Health Genomics; P.M. Gaffney, MD; J.A. Kelly, MPH; J.M. Guthridge PhD; K.L. Moser, PhD, Arthritis and Clinical Immunology Research Program, Oklahoma Medical Research Foundation; K.M. Kaufman, PhD; J.B. Harley, MD, PhD, Division of Rheumatology, Cincinnati Children's Hospital Medical Center; R.P. Kimberly, MD; J.C. Edberg, PhD, Department of Medicine, University of Alabama at Birmingham; T.B. Niewold, MD, Section of Rheumatology and Gwen Knapp Center for Lupus and Immunology Research, University of Chicago; C.O. Jacob, $M D, P h D$, Keck School of Medicine, University of Southern California at Los Angeles; B.P. Tsao, PhD, David Geffen School of Medicine, University of California Los Angeles; G.S. Alarcón, MD, MPH, Departments of Medicine and Epidemiology, Schools of Medicine and Public Health, University of Alabama at Birmingham; E.E. Brown, PhD, MPH, Department of Epidemiology, University of Alabama at Birmingham; M.A. Petri, MD, MPH, Department of Medicine, Johns Hopkins University School of Medicine; R. Ramsey-Goldman, MD, DrPH, Division of Rheumatology, Northwestern University Feinberg School of Medicine; J.D. Reveille, MD, Rheumatology and Clinical Immunogenetics, University of Texas Health Science Center at Houston; L.M. Vilá, MD, Department of Medicine, Division of Rheumatology, University of Puerto Rico Medical Sciences Campus; J.A. James, MD, PhD, Arthritis and Clinical Immunology, Oklahoma Medical Research Foundation, and Department of Medicine, University of Oklahoma Health Sciences Center; J.T. Merrill, MD, Clinical Pharmacology Research Program, Oklahoma Medical Research Foundation; S.A. Boackle, MD, Division of Rheumatology, University of Colorado Denver;

B.I. Freedman, MD, Department of Internal Medicine/Nephrology, Wake Forest School of Medicine; R.H. Scofield, MD, Arthritis and Clinical Immunology, Oklahoma Medical Research Foundation, Department of Medicine, University of Oklahoma Health Sciences Center, and US Department of Veterans Affairs Medical Center; A.M. Stevens, MD, PhD, Division of Rheumatology, Department of Pediatrics, University of Washington Seattle; T.J. Vyse, MA, MBBS, MRCP, PhD, King's College London; L.A. Criswell, MD, MPH, DSc, Rosalind Russell Medical Research Center for Arthritis, University of California, San Francisco; M.E. Alarcón-Riquelme, MD, PhD, Oklahoma Medical Research Foundation, and Centro de Genómica e Investigaciónes Oncológicas, Pfizer-Universidad de Granada-Junta de Andalucia.

Address correspondence to Dr. P.S. Ramos, Division of Rheumatology and Immunology, Medical University of South Carolina, 96 Jonathan Lucas Street, Suite 912, Charleston, SC 29425,USA. E-mail: ramosp@musc.edu Accepted for publication February 14, 2013.

Systemic lupus erythematosus (SLE; MIM 152700) is a chronic, often severe, systemic autoimmune disease characterized by the production of high titers of autoantibodies directed against native DNA and other cellular antigens.
SLE disproportionately affects women and African Americans (AA), i.e., $0.009 \%$ of white men, $0.066 \%$ of white women, $0.038 \%$ of AA men, and $0.282 \%$ of AA women ${ }^{1}$. A genetic contribution to SLE is unequivocal; recent genome-wide association studies in whites and Asians have identified nearly 40 validated susceptibility loci and implicated a broad array of biological pathways ${ }^{2}$. Despite a higher prevalence, incidence, and disease severity ${ }^{3,4}$, little is known about the genetic etiology of SLE in individuals of African ancestry. Recently, large candidate gene studies have uncovered associations of specific loci in $\mathrm{AA}^{5,6,7,8,9}$.

Overproduction of nitric oxide (NO) and reactive oxygen intermediates is implicated in disease pathogenesis. Markers of systemic NO production and reactive oxygen species (ROS) are higher in patients with SLE than in controls; these markers correlate with disease activity, and early studies suggest that failure to suppress these markers associates with lack of clinical response to therapy for lupus nephritis ${ }^{10,11,12}$. These combined observations make NO synthases and other reactive intermediate producing and scavenging genes biological candidates for disease susceptibility.

The Gullah are a unique population of African ancestry in the United States. Their ancestors were forcibly brought from the Sierra Leone and Ivory Coast area in West Africa, and were kept in the geographically isolated Sea Islands along the South Carolina and Georgia coasts ${ }^{13}$. Until recent times, the estimated 100,000 to 300,000 Gullah remained relatively isolated. While continental AA average about $80 \%$ West African and 20\% European ancestry ${ }^{14}$, the white admixture in the Gullah is $<3.5 \%$, and the Gullah are the most homogeneous AA population described ${ }^{15,16,17}$. Interestingly, there is the perception that SLE is rare in Africa, suggesting that comparative studies of related cohorts from the 2 continents may provide insight into the genetic etiology of $\mathrm{SLE}^{18}$. A higher than predicted prevalence of SLE multiplex families and a high prevalence of seropositivity in SLE first-degree relatives was observed in the Gullah, suggesting a major genetic influence in this population ${ }^{19}$. In parallel, studies report a higher prevalence of certain common complex traits in the Gullah when compared to other $\mathrm{AA}^{19,20,21}$. Because of their genetic and environmental homogeneity, low European admixture, and increased prevalence and familial clustering of certain diseases, the Gullah are a unique population for deciphering the African heritability in these diseases. The power to detect associations may be higher in more genetically homogeneous populations, such as the Gullah. Given these advantages of an homogeneous population, we attempted to identify specific genetic variants in genes involved in reactive intermediate production and scavenging predisposing to SLE in the Gullah population and admixed AA.

Personal non-commercial use only. The Journal of Rheumatology Copyright $\odot$ 2013. All rights reserved. 


\section{MATERIALS AND METHODS}

Patients and genotyping. The study population consisted of 1565 SLE cases and 1799 controls of African ancestry from the collaborative Large Lupus Association Study 2 (LLAS2), including Gullah (133 cases and 112 controls) and non-Gullah AA (1432 cases and 1687 controls). All study participants provided written informed consent that was approved by institutional review boards at each institution. Cases met the 1997 American College of Rheumatology (ACR) criteria for $\mathrm{SLE}^{22}$. Race was self-reported. Gullah ancestry was self-identified as AA Gullah from the Sea Islands region of South Carolina and Georgia, with all known grandparents being of Gullah descent ${ }^{19}$.

Genotyping was performed with the LLAS2 project, which involved multiple investigators and > 32,000 single-nucleotide polymorphisms (SNP). A total of 244 SNP from 53 regions harboring genes selected for their role in producing NO, ROS, or scavenging reactive oxygen and nitrogen species were analyzed (data available from author on request). SNP were chosen for their position and function in each gene, with priority given to those with potentially stronger phenotypic risks (data available from author on request). SNP were genotyped on a customized Illumina Infinium II platform.

Statistical analyses. Only SNP meeting the quality control criteria of $<10 \%$ overall missing data, no evidence of differential missingness between cases and controls $(p>0.05)$, consistency with Hardy-Weinberg equilibrium genotype frequency expectations ( $\mathrm{p}<0.01$ controls, $\mathrm{p}<0.0001$ cases $)$, and minor allele frequency (MAF) $>5 \%$ were included. Related and duplicate individuals were removed and sex inconsistencies and heterozygosity outliers excluded. Potential confounding substructure or admixture was controlled for using 306 ancestry informative markers to compute admixture proportions as implemented in the Admixmap program; principal component analysis using all SNP confirmed the results. After adjustment for population substructure, the inflation factor using all SNP was $\lambda=0.98$ in the Gullah and $\lambda=1.19$ in the AA. Principal component analysis plots of the AA and Gullah samples were conducted (data available from the author on request). Although the higher inflation factor would be expected given the selection of SNP in candidate genes, a genomic controladjusted $\mathrm{p}$ value was also computed in AA. In contrast, the $\lambda$ value close to 1 in the Gullah ensured that false-positive associations due to population stratification were excluded.

The computer program SNPGWA was used for the association analysis (Division of Public Health Sciences, Wake Forest School of Medicine; www.phs.wfubmc.edu/public/bios/gene/home.cfm). The additive genetic model is reported unless the lack-of-fit test for the additive model reached significance $(\mathrm{p}<0.05)$. In that case, the minimum $\mathrm{p}$ value from the additive, recessive, and dominant genetic models is reported. Tests can be affected by low genotype counts; therefore, a minimum of 30 homozygotes and 10 homozygotes for the minor allele were required to consider the recessive or additive models, respectively. Genetic models were defined relative to the minor allele, and reported results were adjusted for population substructure. In addition to the joint analysis of AA and Gullah samples, a weighted $\mathrm{Z}$ score metaanalysis was computed as implemented in METAL software (Center for Statistical Genetics, University of Michigan; www.sph.umich.edu/csg/abecasis/metal), with weights being the square root of the sample size for each dataset; thus, the metaanalysis incorporates direction, magnitude of association, and sample size.

To uncover potential haplotype associations, a sliding window haplotype analysis of 3 to 8 SNP was performed in each region. A logistic regression model was employed, adjusting for population structure as implemented in PLINK software (Harvard University; pngu.mgh. harvard.edu/ purcell/plink $)^{23}$. Haplotypes with frequency $<10 \%$ were excluded.

To test for 2-locus interactions among SNP, all reported results met the quality criteria defined above. Specifically, SAS software (SAS Institute Inc.) was used to compute a logistic regression model, with each SNP modeled under an additive genetic model and the interaction as the centered crossproduct of the SNP under the additive model. To reduce false-positive interactions due to low MAF, we rejected all pairs for which the expected number of individuals in the dataset was $<5$ for minor allele homozygotes. In addition, all SNP pairs with a linkage disequilibrium (LD) measure of $\mathrm{r}^{2}$ $>0.2$ in YRI (a West African ancestry population) were excluded. Interactions were adjusted for population substructure. For chromosome X, only females were included.

A power analysis was computed with Quanto (University of Southern California; hydra.usc.edu/gxe) using a prevalence of $0.1 \%$ and $\alpha=0.01$. LD between SNP was assessed with SNAP software using data from the 1000 Genomes Project in YRI (Broad Institute; www.broadinstitute.org/ $\mathrm{mpg} / \mathrm{snap} /$ index.php). SNP functionality was evaluated with the University of California at Santa Cruz (UCSC) genome browser (genome.ucsc.edu).

\section{RESULTS}

Genes with known association with production of or regulation of reactive oxygen and nitrogen intermediates were selected (data available from author on request). SNP mapping to 53 regions harboring reactive intermediate related genes were identified (data available from author on request). Association was assessed between these 244 SNP and SLE in the Gullah (133 cases and 112 controls) and AA populations (1432 cases and 1687 controls).

The most significant single-marker associations are shown in Table 1 . To minimize potentially spurious associations, effects that were not supported by associations at neighboring SNP were excluded (Figure 1). In admixed AA, the most significant association was identified in the glutathione reductase (GSR) gene. In the Gullah, the most significant associations mapped to the $N A D H$ dehydrogenase (ubiquinone) $\mathrm{Fe}-\mathrm{S}$ protein 4, $18 \mathrm{kDa}$ (NADH-coenzyme Q reductase; NDUFS4), and NO synthase 1 (NOS1) genes. It should be noted that the variants reported here as associated with SLE met quality control thresholds in both AA and Gullah populations, but revealed association in only one of the populations (Figure 2).

The strongest signal in AA was observed at an intronic variant in a DNAseI hypersensitive cluster in the GSR gene $\left(\mathrm{rs} 2253409 ; \mathrm{p}=1.43 \times 10^{-03}\right.$, OR $1.26,95 \%$ CI $\left.1.09-1.44\right)$. Although modest, other associations with neighboring SNP corroborated the association observed at rs2253409, suggesting it is unlikely to be spurious (Figure 1). Samples had $74 \%$ power to detect this effect. Despite meeting quality control thresholds, rs2253409 was not associated in the Gullah (Figure 2).

In the Gullah, the most significant association was an intronic risk variant in the NDUFS4 gene (rs381575; p = $6.51 \times 10^{-03}$, OR $2.1,95 \%$ CI 1.23-3.59). Interestingly, this SNP locates in the transcription factor binding site for the RE1-silencing transcription factor and GATA1 and GATA3 proteins. An intronic variant with a protective effect in NOS1 was also identified in the Gullah (rs561712; $\mathrm{p}=7.18$ $\times 10^{-03}$, OR $0.62,95 \%$ CI $0.44-0.88$ ). Despite modest power (58\% and $45 \%$ power to detect the effects reported for NDUFS4 and NOS1, respectively), it is noteworthy that both the NDUFS4 and NOS1 associations were corroborated by associations at neighboring SNP (Figure 1). These variants

Personal non-commercial use only. The Journal of Rheumatology Copyright (C) 2013. All rights reserved. 
Table 1. SNP with the most significant association with SLE.

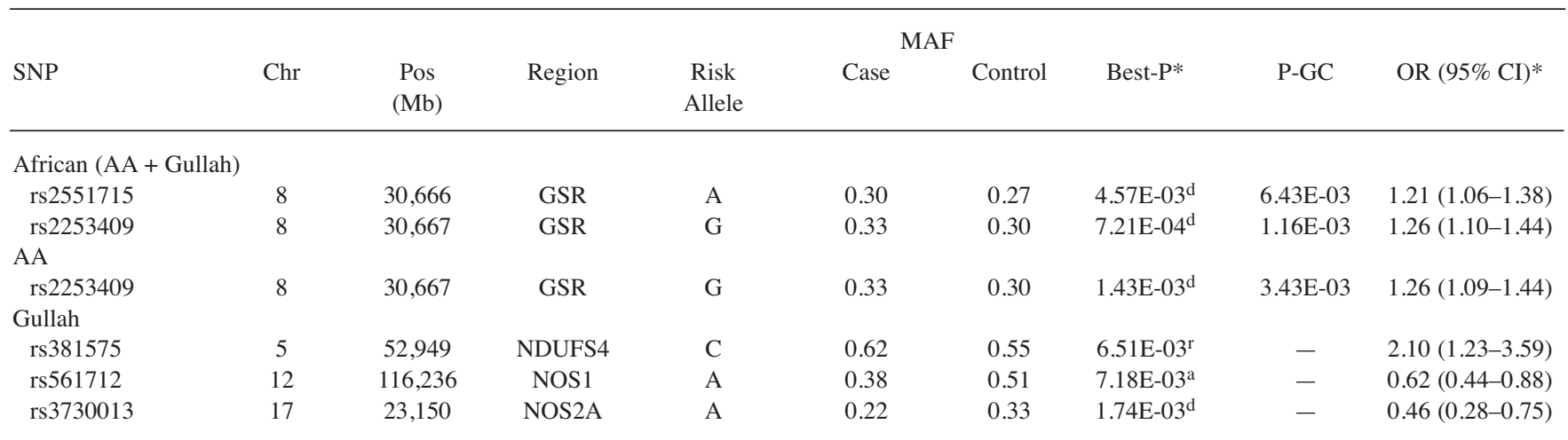

* Best-P, OR, and CI reported under the following genetic models: ${ }^{\mathrm{a}}$ additive, ${ }^{\mathrm{d}}$ dominant, ${ }^{\mathrm{r}}$ recessive. Chr: chromosome; Pos: position; MAF: minor allele frequency; P-GC: best-P after a genomic control adjustment; SNP: single-nucleotide polymorphism; AA: African American; GSR: glutathione reductase; NDUF: nicotinamide adenin dinucleoacid hydrogen; NOS: nitric oxide synthase; SLE: systemic lupus erythematosus.
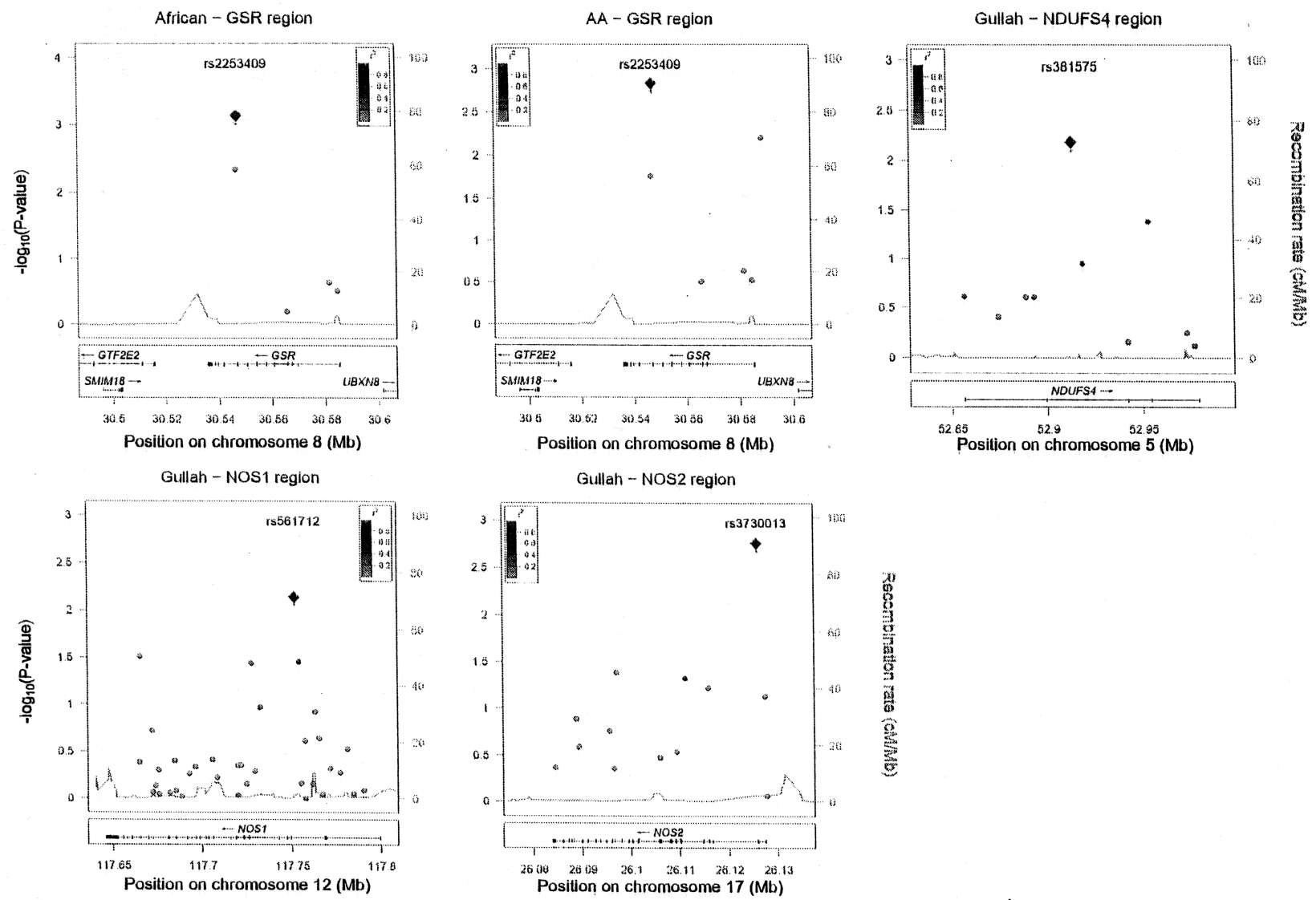

Figure 1. Regional plots of reactive intermediate gene loci in African, African American (AA), and Gullah populations. Genotyped SNP are plotted with their $\mathrm{p}$ values [as $-\log _{10}$ ( $\mathrm{p}$ values)] as a function of genomic position (Human Genome Build 18) within a region surrounding the most significant SNP (black diamond). Recombination rates from the 1000 Genomes AFR (11/2010) are plotted in gray to reflect the regional linkage disequilibrium (LD) structure. In each region the index SNP is represented by a large black diamond, and the shade of all other SNP (circles) indicates LD with the index SNP based on pairwise $\mathrm{r}^{2}$ values from the 1000 Genomes AFR study. Known human genes in the University of California at Santa Cruz Genome Browser are at the bottom. GSR: glutathione reductase gene; NOS: nitric oxide synthase.

also met quality control thresholds in AA, but were associated only with SLE in the Gullah (Figure 2).

Combining all samples of African ancestry (AA and
Gullah) in a joint analysis, the signals identified in the AA predominated, as expected given their larger sample size. Table 1 reveals that in the African population, among the top 

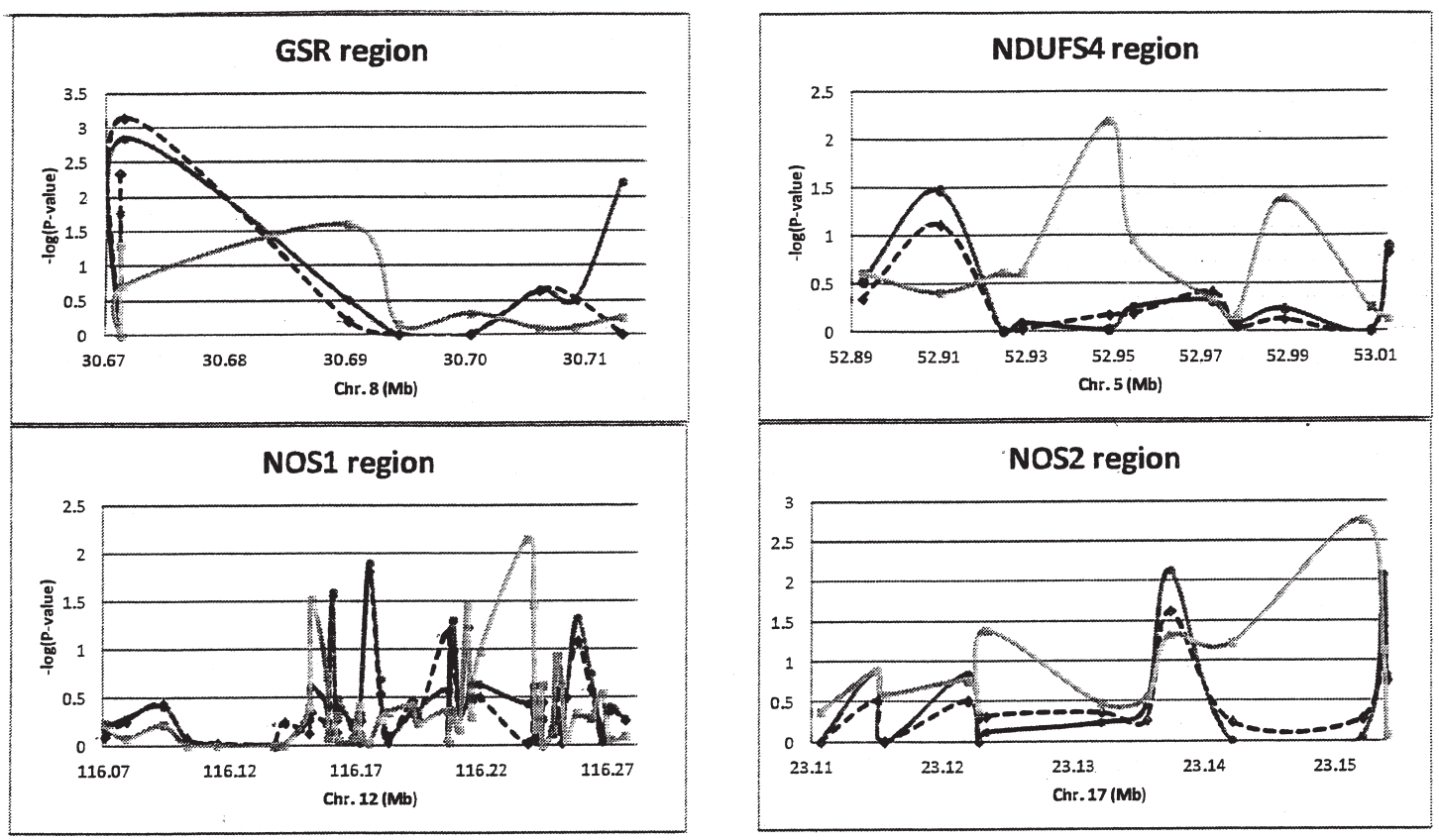

Figure 2. Patterns of association results of reactive intermediate gene loci in African, African American, and Gullah populations. Association results are shown for the Gullah (gray solid line), African American (black solid line), and combined African (dashed black line). Genotyped SNP (symbols) are plotted with their p values [as $-\log _{10}(\mathrm{p}$ values)] as a function of genomic position $(\mathrm{Mb})$ in each gene's region. GSR: glutathione reductase gene; NOS: nitric oxide synthase.

associations were the aforementioned variant in $G S R$ $\left(\mathrm{rs} 2253409 ; \mathrm{p}=7.21 \times 10^{-04}\right.$, OR $1.26,95 \%$ CI $\left.1.10-1.44\right)$ and another intronic variant in GSR (rs2551715; $\mathrm{p}=4.57 \times$ $10^{-03}$, OR $1.21,95 \%$ CI $\left.1.06-1.38\right)$ not in LD with the former $\left(r^{2}=0.07\right.$ in YRI). Very similar results were obtained when a metaanalysis of the AA and Gullah results was computed (rs2253409, $\mathrm{p}=6.85 \times 10^{-04} ; \mathrm{rs} 2551715, \mathrm{p}=4.49$ $\times 10^{-03}$ ). The samples had $57 \%$ and $77 \%$ power to detect the effects reported for the first and second variants in GSR, respectively. Figure 2 shows how the patterns of association for the reported genes vary among the AA, Gullah, and combined African populations.

Among the cases of SLE, $42 \%$ of the 1527 total AA and $46 \%$ of the 152 total Gullah cases show renal involvement. Keeping in mind the smaller sample sizes and reduced power to detect associations, testing for association of these SNP with lupus nephritis showed very modest associations: GSR in African (rs2253409, $\mathrm{p}=0.01$ ) and AA (rs2253409, $\mathrm{p}=0.01)$ and NOS1 in African (rs10850803, $\mathrm{p}=0.01)$ and AA (rs10850803, p = 0.007).

Haplotype-association methods may have more power and accuracy than single markers to detect disease effects. As shown in Table 2, the most significant haplotype association detected in AA and combined African samples was a 3-SNP haplotype in an intronic NOS1 region (rs3741476, rs1875140, and rs1077490; $\mathrm{p}=2.87 \times 10^{-04}$, frequency 0.21 , OR 1.32 in $\mathrm{AA}$; and $\mathrm{p}=7.36 \times 10^{-04}$, frequency 0.21 , OR 1.28 in all samples with African ancestry). A 4-SNP protective haplotype in an intronic glutathione synthetase (GSS) region was also uncovered (rs6087651, rs2236270, rs17092180, and rs2273684; $\mathrm{p}=$ $2.65 \times 10^{-04}$, frequency 0.14 , OR 0.73 in $\mathrm{AA}$; and $\mathrm{p}=1.71$ $\times 10^{-04}$, frequency 0.15 , OR 0.73 in African). No significant haplotypes were identified in the Gullah population.

Table 3 shows the most significant 2-locus interaction analysis results. Nearly all interactions were specific to one ethnic group or the other. Only an interaction between an NDUFS2 variant (rs4656993) with a minichromosome maintenance complex component 5 SNP (rs4645794) was observed in the combined African samples ( $\mathrm{p}=4.00 \times 10^{-04}$, OR $1.34,95 \%$ CI $1.27-1.40)$ and $\mathrm{AA}\left(\mathrm{p}=9.74 \times 10^{-05}, \mathrm{OR}\right.$ $1.40,95 \%$ CI $1.32-1.48)$.

\section{DISCUSSION}

This is the first comprehensive analysis of reactive intermediate genes for their association with SLE in populations of African ancestry. Despite relatively modest power, strict quality criteria filters were applied to reduce the likelihood of false-positive associations. In the Gullah, the virtually perfect inflation factor ensures that false-positive associations due to population stratification can be conclusively excluded. Despite the small sample size of the Gullah being a limitation of our study, all the associations reported were corroborated by associations at SNP in LD with the top 
Table 2. Haplotypes with the most significant association with SLE.

\begin{tabular}{|c|c|c|c|c|c|c|c|c|c|}
\hline NSNP & Size $(\mathrm{kb})$ & SNP1 & $\mathrm{Chr}$ & Pos & Haplotype* & $\mathrm{F}$ & OR & $\mathrm{p}$ & Region \\
\hline \multicolumn{10}{|c|}{ African (AA + Gullah) } \\
\hline 3 & 2.0 & rs3741476 & 12 & 116156518 & $\mathrm{GAG}^{\mathrm{a}}$ & 0.21 & 1.28 & 7.36E-04 & NOS1 \\
\hline \multicolumn{10}{|l|}{ AA } \\
\hline 3 & 2.0 & rs3741476 & 12 & 116156518 & $\mathrm{GAG}^{\mathrm{a}}$ & 0.21 & 1.32 & $2.87 \mathrm{E}-04$ & NOS1 \\
\hline 4 & 11.4 & rs6087651 & 20 & 32982014 & $\mathrm{GCGC}^{\mathrm{b}}$ & 0.14 & 0.73 & $2.65 \mathrm{E}-04$ & GSS \\
\hline
\end{tabular}

* Haplotype defined by SNP: ${ }^{a}$ rs3741476-rs1875140-rs10774909; b rs6087651-rs2236270-rs17092180-rs2273684. SLE: systemic lupus erythematosus; AA: African American; NSNP: number of single-nucleotide polymorphisms in haplotype; size: size of the haplotype; SNP1: first SNP on haplotype; Chr: chromosome; Pos: position of the first SNP in haplotype; F: frequency of haplotype; GSS: intronic glutathione synthetase; NOS: nitric oxide synthase.

Table 3. Most significant 2-loci interaction analysis results. Interactions due to linkage disequilibrium were excluded, as well as interactions where the expected number of individuals homozygous for both minor alleles was $<5$ in both cases and controls (to avoid potentially spurious interactions).

\begin{tabular}{|c|c|c|c|c|c|c|c|c|c|}
\hline SNP1 & Chr1 & Pos1 (bp) & Region1 & SNP2 & $\mathrm{Chr} 2$ & Pos2 (bp) & Region 2 & $\mathrm{p}$ & OR $(95 \% \mathrm{CI})$ \\
\hline \multicolumn{10}{|l|}{ African } \\
\hline rs4656993 & 1 & 159442761 & NDUFS2 & rs4645794 & 22 & 34142051 & HMOX1, MCM5 & $4.00 \mathrm{E}-04$ & $1.34(1.27-1.40)$ \\
\hline \multicolumn{10}{|l|}{ AA } \\
\hline rs4656993 & 1 & 159442761 & NDUFS2 & rs4645794 & 22 & 34142051 & HMOX1, MCM5 & $9.74 \mathrm{E}-05$ & $1.40(1.32-1.48)$ \\
\hline rs 561712 & 12 & 116236452 & NOS1 & rs 728546 & 16 & 68013029 & CYB5B & $5.00 \mathrm{E}-04$ & $0.67(0.61-0.73)$ \\
\hline \multicolumn{10}{|l|}{ Gullah } \\
\hline $\mathrm{rs} 256094$ & 5 & 53008681 & NDUFS4 & rs133415 & 22 & 34136238 & HMOX1, MCM5 & $2.00 \mathrm{E}-04$ & $0.31(0.15-0.64)$ \\
\hline
\end{tabular}

Chr: chromosome; Pos: position; SNP: single-nucleotide polymorphism; AA: African American; NDUF: nicotinamide adenin dinucleoacid hydrogen; NOS: nitric oxide synthase; CYP: cytochrome; SOD: superoxide dismutase; HMOX: heme oxygenase; MCM: minichromosome maintenance complex; CYB5B: cytochrome b5 type B.

associated SNP, underscoring that these associations are not genotyping artifacts.

The genes chosen were of interest because they all had the potential to affect reactive intermediate production or clearance/scavenging. ROS can oxidatively modify proteins to influence their activity. Transcription factors AP1 (cJun), nuclear factor- $\kappa \mathrm{B}(\mathrm{NF}-\kappa \mathrm{B})$, hypoxia-inducible factor- $1 \alpha$, and p53 are all redox-regulated ${ }^{24}$. For instance, $\mathrm{H}_{2} \mathrm{O}_{2}$ generated by endothelial cell (EC) NOX leads to NF- $\mathrm{KB}$-mediated transcription of intercellular adhesion molecule and vascular cell adhesion molecule ${ }^{25}$, both of which associate with lupus nephritis disease activity 26,27 and atherosclerosis ${ }^{28,29}$. Two inflammatory cytokines, interleukin 6 (IL-6) and monocyte chemoattractant proteins 1 (MCP-1; CCL2), important to the pathogenesis of lupus nephritis ${ }^{30,31,32,33,34,35}$ and atherosclerosis ${ }^{36,37}$, have in common redox-regulated NF- $\kappa \mathrm{B}$ response elements (UCSC Genome browser). Both MCP-1 and IL-6 secretion by activated EC is dependent on ROS production and can be inhibited by ROS scavengers ${ }^{38}$.

The functional relevance of the described SNP in reactive intermediate genes is not known. However, reductions in the activity or expression of functionally protective genes could predispose to SLE, SLE disease activity, or target organ damage. SLE is associated with increased markers of oxidative stress, particularly among $\mathrm{AA}^{10,39,40}$. The consequences of this increased oxidative stress may be increased antigenicity of self-antigens and pathogenic redox signaling.

GSR catalyzes the reduction of glutathione disulfide to glutathione $(\mathrm{GSH})$, an important antioxidant molecule ${ }^{41}$. Glutathione synthetase catalyzes the production of glutathione itself. Reduced levels of GSH can lead to increased oxidant stress. Of significance to SLE, lower levels of reduced GSH were observed in $\mathrm{T}$ cells from patients with SLE, in association with mitochondrial hyperpolarization and ATP depletion $^{42}$, a process that can predispose cells to necrosis. Our study does not address whether the reduced levels of GSH observed in patients with SLE is due to increased production of ROS, reduced enzyme activity, or both.

The proteins encoded by NDUFS 2 and NDUFS4 are subunits of the mitochondrial membrane respiratory chain NADH dehydrogenase (complex I). Reports are conflicting; however, defects in NDUFS2 can lead to increased reactive intermediate production ${ }^{43}$, while described mutations in NDUFS4 do not appear to lead to increased oxidative stress $^{44}$. 
Low levels of NO produced by NOS3, also known as endothelial nitric oxide synthase (eNOS), are protective in vascular disease and inflammation. Expression of NOS3 is reduced in proliferative lupus nephritis ${ }^{45}$, and the effects of low-level NO production are functionally reduced in the vasculature of patients with SLE ${ }^{46}$. Similarly, NOS1 appears to prevent leukocyte adhesion in mice lacking $\mathrm{NOS}^{47}$. This finding is also seen in disease, because in both humans and mice with cirrhosis, NOSI (normally expressed in vascular smooth muscle cells $)^{48}$ is upregulated in eNOS (NOS3) deficiency, suggesting that NOS1 can compensate for reduced eNOS activity ${ }^{49}$. Thus, NOS1 deficiency could exacerbate NOS3 dysfunction or deficiency, leading to inflammation and vascular dysfunction. There is evidence for this notion, because NOS1 is associated with endstage renal disease in $\mathrm{AA}^{50}$.

We uncovered several novel associations of reactive intermediate-related genes with SLE in patients with African ancestry. We show that many of the loci associated with SLE differ in Gullah and AA, suggesting that specific loci may be more strongly associated in specific populations with African ancestry. This is not a surprising finding given the great genetic diversity present on the African continent ${ }^{51,52}$. These results suggest that patterns of disease association for SLE may be distinct and specific loci may be more strongly SLE-associated in select African ancestry populations.

\section{ACKNOWLEDGMENT}

We thank the patients with SLE and the controls who participated in our study. We are thankful to the research assistants, coordinators, and physicians who helped in the recruitment of participants. We also thank Dr. Peter $\mathrm{K}$. Gregersen for contributing control samples genotyped in our study.

\section{REFERENCES}

1. Helmick CG, Felson DT, Lawrence RC, Gabriel S, Hirsch R, Kwoh $\mathrm{CK}$, et al. Estimates of the prevalence of arthritis and other rheumatic conditions in the United States. Part I. Arthritis Rheum 2008;58:15-25

2. Deng Y, Tsao BP. Genetic susceptibility to systemic lupus erythematosus in the genomic era. Nat Rev Rheumatol 2010; 6:683-92.

3. Alarcon GS, Friedman AW, Straaton KV, Moulds JM, Lisse J, Bastian HM, et al. Systemic lupus erythematosus in three ethnic groups: III. A comparison of characteristics early in the natural history of the LUMINA cohort. LUpus in MInority populations: NAture vs. Nurture. Lupus 1999;8:197-209.

4. Siegel M, Lee SL. The epidemiology of systemic lupus erythematosus. Semin Arthritis Rheum 1973;3:1-54.

5. Zhao J, Wu H, Khosravi M, Cui H, Qian X, Kelly JA, et al. Association of genetic variants in complement factor $\mathrm{H}$ and factor H-related genes with systemic lupus erythematosus susceptibility. PLoS Genetics 2011;7:e1002079.

6. Ruiz-Narvaez EA, Fraser PA, Palmer JR, Cupples LA, Reich D, Wang YA, et al. MHC region and risk of systemic lupus erythematosus in African American women. Hum Genet 2011;130:807-15.

7. Sanchez E, Comeau ME, Freedman BI, Kelly JA, Kaufman KM, Langefeld CD, et al. Identification of novel genetic susceptibility loci in African American lupus patients in a candidate gene association study. Arthritis Rheum 2011;63:3493-501.

8. Lessard CJ, Adrianto I, Ice JA, Wiley GB, Kelly JA, Glenn SB, et al. Identification of IRF8, TMEM39A, and IKZF3-ZPBP2 as susceptibility loci for systemic lupus erythematosus in a large-scale multiracial replication study. Am J Hum Genet 2012;90:648-60.

9. Adrianto I, Wang S, Wiley GB, Lessard CJ, Kelly JA, Adler AJ, et al. Association of two independent functional risk haplotypes in TNIP1 with systemic lupus erythematosus. Arthritis Rheum 2012;64:3695-705.

10. Oates JC. The biology of reactive intermediates in systemic lupus erythematosus. Autoimmunity 2010;43:56-63.

11. Oates JC, Shaftman SR, Self SE, Gilkeson GS. Association of serum nitrate and nitrite levels with longitudinal assessments of disease activity and damage in systemic lupus erythematosus and lupus nephritis. Arthritis Rheum 2008;58:263-72.

12. Wang G, Pierangeli SS, Papalardo E, Ansari GA, Khan MF. Markers of oxidative and nitrosative stress in systemic lupus erythematosus: correlation with disease activity. Arthritis Rheum 2010;62:2064-72.

13. Opala J. The Gullah: Rice, slavery, and the Sierra Leone-American connection. Fort Sumter National Monument, Sullivans Island, South Carolina: US Park Service; 2000.

14. Smith MW, Patterson N, Lautenberger JA, Truelove AL, McDonald GJ, Waliszewska A, et al. A high-density admixture map for disease gene discovery in African Americans. Am J Hum Genet 2004;74:1001-13.

15. Garvey WT, McClean DC, Spruill I. The search for obesity genes in isolated populations: Gullah-speaking African Americans and the role of uncoupling protein 3 as a thrifty gene. In: Medeiros G, Halpern A, Bouchard C, editors. Progress in obesity research. Paris: John Libbey Eurotext; 2003:373-80.

16. Parra EJ, Kittles RA, Argyropoulos G, Pfaff CL, Hiester K, Bonilla $\mathrm{C}$, et al. Ancestral proportions and admixture dynamics in geographically defined African Americans living in South Carolina. Am J Phys Anthropol 2001;114:18-29.

17. McLean DC Jr, Spruill I, Gevao S, Morrison EY, Bernard OS, Argyropoulos G, et al. Three novel mtDNA restriction site polymorphisms allow exploration of population affinities of African Americans. Hum Biol 2003;75:147-61.

18. Gilkeson G, James J, Kamen D, Knackstedt T, Maggi D, Meyer A, et al. The United States to Africa lupus prevalence gradient revisited. Lupus 2011;20:1095-103.

19. Kamen DL, Barron M, Parker TM, Shaftman SR, Bruner GR, Aberle T, et al. Autoantibody prevalence and lupus characteristics in a unique African American population. Arthritis Rheum 2008;58:1237-47.

20. Sale MM, Lu L, Spruill IJ, Fernandes JK, Lok KH, Divers J, et al. Genome-wide linkage scan in Gullah-speaking African American families with type 2 diabetes: The Sea Islands Genetic African American Registry (Project SuGAR). Diabetes 2009;58:260-7.

21. Fernandes JK, Wiegand RE, Salinas CF, Grossi SG, Sanders JJ, Lopes-Virella MF, et al. Periodontal disease status in Gullah African Americans with type 2 diabetes living in South Carolina. J Periodontol 2009;80:1062-8

22. Hochberg MC. Updating the American College of Rheumatology revised criteria for the classification of systemic lupus erythematosus. Arthritis Rheum 1997;40:1725.

23. Purcell S, Neale B, Todd-Brown K, Thomas L, Ferreira MA, Bender D, et al. PLINK: A tool set for whole-genome association and population-based linkage analyses. Am J Hum Genet 2007;81:559-75

24. Sun Y, Oberley LW. Redox regulation of transcriptional activators Free Radic Biol Med 1996;21:335-48.

25. Cai $\mathrm{H}$. Hydrogen peroxide regulation of endothelial function:

Personal non-commercial use only. The Journal of Rheumatology Copyright $\odot$ 2013. All rights reserved. 
Origins, mechanisms, and consequences. Cardiovasc Res 2005;68:26-36.

26. Singh S, Wu T, Xie C, Vanarsa K, Han J, Mahajan T, et al. Urine VCAM-1 as a marker of renal pathology activity index in lupus nephritis. Arthritis Res Ther 2012;14:R164.

27. Wuthrich RP, Jevnikar AM, Takei F, Glimcher LH, Kelley VE. Intercellular adhesion molecule-1 (ICAM-1) expression is upregulated in autoimmune murine lupus nephritis. Am J Pathol 1990;136:441-50.

28. Frank PG, Lisanti MP. ICAM-1: Role in inflammation and in the regulation of vascular permeability. Am J Physiol Heart Circ Physiol 2008;295:H926-7.

29. Ley K, Huo Y. VCAM-1 is critical in atherosclerosis. J Clin Invest 2001;107:1209-10.

30. Kulkarni O, Pawar RD, Purschke W, Eulberg D, Selve N, Buchner $\mathrm{K}$, et al. Spiegelmer inhibition of CCL2/MCP-1 ameliorates lupus nephritis in MRL-(Fas)lpr mice. J Am Soc Nephrol 2007; 18:2350-8.

31. Li Y, Tucci M, Narain S, Barnes EV, Sobel ES, Segal MS, et al. Urinary biomarkers in lupus nephritis. Autoimmun Rev 2006;5:383-8.

32. Kiberd BA. Interleukin-6 receptor blockage ameliorates murine lupus nephritis. J Am Soc Nephrol 1993;4:58-61.

33. Brunner HI, Bennett MR, Mina R, Suzuki M, Petri M, Kiani AN, et al. Association of noninvasively measured renal protein biomarkers with histologic features of lupus nephritis. Arthritis Rheum 2012;64:2687-97.

34. Wada T, Yokoyama H, Su SB, Mukaida N, Iwano M, Dohi K, et al. Monitoring urinary levels of monocyte chemotactic and activating factor reflects disease activity of lupus nephritis. Kidney Int 1996;49:761-7.

35. Marks SD, Williams SJ, Tullus K, Sebire NJ. Glomerular expression of monocyte chemoattractant protein-1 is predictive of poor renal prognosis in pediatric lupus nephritis. Nephrol Dial Transplant 2008;23:3521-6.

36. de Lemos JA, Morrow DA, Sabatine MS, Murphy SA, Gibson CM, Antman EM, et al. Association between plasma levels of monocyte chemoattractant protein-1 and long-term clinical outcomes in patients with acute coronary syndromes. Circulation 2003; 107:690-5.

37. Asanuma Y, Chung CP, Oeser A, Shintani A, Stanley E, Raggi P. Increased concentration of proatherogenic inflammatory cytokines in systemic lupus erythematosus: Relationship to cardiovascular risk factors. J Rheumatol 2006;33:539-45.

38. Volk T, Hensel M, Schuster H, Kox WJ. Secretion of MCP-1 and IL-6 by cytokine stimulated production of reactive oxygen species in endothelial cells. Mol Cell Biochem 2000;206:105-12.

39. Griffiths HR. Is the generation of neo-antigenic determinants by free radicals central to the development of autoimmune rheumatoid disease? Autoimmun Rev 2008;7:544-9.
40. Rasheed Z, Khan MW, Ali R. Hydroxyl radical modification of human serum albumin generated cross reactive antibodies. Autoimmunity 2006;39:479-88.

41. Meister A. Glutathione metabolism and its selective modification. J Biol Chem 1988;263:17205-8.

42. Gergely P Jr, Grossman C, Niland B, Puskas F, Neupane H, Allam $\mathrm{F}$, et al. Mitochondrial hyperpolarization and ATP depletion in patients with systemic lupus erythematosus. Arthritis Rheum 2002;46:175-90.

43. Ngu LH, Nijtmans LG, Distelmaier F, Venselaar H, van Emst-de Vries SE, van den Brand MA, et al. A catalytic defect in mitochondrial respiratory chain complex I due to a mutation in NDUFS2 in a patient with Leigh syndrome. Biochim Biophys Acta 2012;1822:168-75.

44. Iuso A, Scacco S, Piccoli C, Bellomo F, Petruzzella V, Trentadue R, et al. Dysfunctions of cellular oxidative metabolism in patients with mutations in the NDUFS1 and NDUFS4 genes of complex I. J Biol Chem 2006;281:10374-80.

45. Furusu A, Miyazaki M, Abe K, Tsukasaki S, Shioshita K, Sasaki O, et al. Expression of endothelial and inducible nitric oxide synthase in human glomerulonephritis. Kidney Int 1998;53:1760-8.

46. El-Magadmi M, Bodill H, Ahmad Y, Durrington PN, Mackness M, Walker M, et al. Systemic lupus erythematosus: An independent risk factor for endothelial dysfunction in women. Circulation 2004;110:399-404.

47. Sanz MJ, Hickey MJ, Johnston B, McCafferty DM, Raharjo E, Huang PL, et al. Neuronal nitric oxide synthase (NOS) regulates leukocyte-endothelial cell interactions in endothelial NOS deficient mice. Br J Pharmacol 2001;134:305-12.

48. Webb GD, Lim LH, Oh VM, El Oakley R, Lee CN, Wong PS, et al. Expression of neuronal nitric oxide synthase in the internal thoracic artery and saphenous vein. J Thorac Cardiovasc Surg 2006;132:1131-6.

49. Biecker E, Neef M, Sagesser H, Shaw S, Koshy A, Reichen J. Nitric oxide synthase 1 is partly compensating for nitric oxide synthase 3 deficiency in nitric oxide synthase 3 knock-out mice and is elevated in murine and human cirrhosis. Liver Int 2004; 24:345-53.

50. Freedman BI, Yu H, Anderson PJ, Roh BH, Rich SS, Bowden DW. Genetic analysis of nitric oxide and endothelin in end-stage renal disease. Nephrol Dial Transplant 2000;15:1794-800.

51. Jorde LB, Watkins WS, Bamshad MJ, Dixon ME, Ricker CE, Seielstad MT, et al. The distribution of human genetic diversity: A comparison of mitochondrial, autosomal, and Y-chromosome data. Am J Hum Genet 2000;66:979-88.

52. Tishkoff SA, Reed FA, Friedlaender FR, Ehret C, Ranciaro A, Froment A, et al. The genetic structure and history of Africans and African Americans. Science 2009;324:1035-44. 
Variable Association of Reactive Intermediate Genes with Systemic Lupus Erythematosus in Populations with Different African Ancestry

Ramos PS, Oates JC, Kamen DL, Williams AH, Gaffney PM, Kelly JA, et al. Variable association of reactive intermediate genes with systemic lupus erythematosus in populations with different African ancestry. J Rheumatol 2013;40:842-9. The following grant information should be included in the funding sources: P60 AR062755 (PSR, JCO, DLK, GSG). We regret the error.

doi:10.3899/jrheum.120989.C1 